DOI: 10.20472/TEC.2017.004.003

NADER ELSHEMY

Arab Open University AOU, Oman

\title{
IMPACT OF GAMIFICATION STRATEGY ON ACADEMIC ACHIEVEMENT AND ACHIEVEMENT MOTIVATION TOWARD LEARNING
}

\begin{abstract}
:
The current study aims to determine the effect of Gamification strategy on academic achievement and achievement motivation among students of the second stage of basic education in Muscat Governorate. The current research sample has reached (68) students divided into an experimental group (34) and a control group (34). The quasi-experimental approach has been used for the application of the study, as well as the descriptive analytical methodology for the analysis \& interpretation of previous Arabic and foreign studies addressing the subject of Gamification strategy, motivation and academic achievement. To assess such effect, researchers have used an educational electronic game for the application of Gamification strategy, motivation scale and achievement test (pre $\&$ post). The study found the existence of statistically significant differences at a level of significance ( $\alpha=0.05$ ) between the experimental group and the control group in the increase of motivation for the experimental group, in addition to the existence of statistically significant differences at a level of significance $(\alpha=0.05)$ between the experimental group and the control group in the increase of academic achievement for the experimental group.
\end{abstract}

\section{Keywords:}

e-Content, Gamification, Motivation

JEL Classification: 129 


\section{INTRODUCTION}

Education is the foundation for nations' renaissance and the secret of their development, so we must cope with current developments and work on the development of education to meet the needs of the stage we are going through. The basic educational stage is an important stage in the life of an individual due to its impact on the formation of his character, as it is the period in which his mental \& skill abilities grow and he determines his attitudes; therefore the individual needs to interact and participate with the educational process elements both inside and outside the classroom.

The field of teaching methods \& strategies has saw a diversity in the latest strategies aiming to raise motivation among students towards education by attracting their attention to the educational subjects and putting it in a mold which is accepted and positively interacted with by the student, creating an interactive participatory educational environment, and this enhances the pupils' self-confidence and their satisfaction with education.

What many students known about traditional education is that it is ineffective and boring, however, teachers are always looking for new ways of teaching, but it is agreed that schools today face a great difficulty in attracting and motivating students to learn. The importance of games usage in education lies in its ability to strengthen the knowledge and develop skills of the learner, and the development of cooperation \& communication between learners, in addition to having a wonderful motivational force where a number of games is used to encourage people to interact at no charge but just for the fun of playing and winning probability. Nevertheless, to innovate an educational game is a long, time-consuming and costly matter, where the game designer targets a group of learners having special characteristics taking into account the achievement of learning objectives as well as the need for a technological infrastructure in classrooms for its application. The use of comprehensive games requires a great deal of design and development efforts, where Gamification methodology suggests the usage \& designing of gaming elements to improve the participation and motivation of the learner (Dicheva, Dichev, Agre, Angelova, 2015).

Therefore, we must apply modern strategies which are suitable for the digital generation, increasing its motivation and encouraging the behaviors to be achieved through the educational objectives including Gamification strategy which concept has appeared in marketing fields, but it is adopted in many fields, particularly education, because it helps teachers find a balance between achieving the educational goals in addition to fulfilling the evolving needs of learners. (Hsin, Huang, Soman, 2013).

The current research aims to determine the effect of using Gamification on the motivation of the students from the second stage of basic education. 


\section{STUDY PROBLEM}

Through researchers' work in the educational field as teachers and educational supervisors, they noticed that students feel boredom and lack of concentration during the explanation if the teacher uses traditional methods of teaching which lead to the lack of learner's desire in interacting with the teacher as well as his colleagues; whilst they noticed if the teacher uses teaching methods attracting students' attention such as display tools attracting learners' attention or educational games, students interact with it so that it increases their self-confidence. Researchers noticed the impact of low motivation on academic achievement among students through assessment tools and, most importantly, examinations results; to make sure thereof, researchers have made a questionnaire, to analyze learners' needs, distributed to students of the second stage of basic education, where it showed that students mostly tend to applied materials and can't absorb large amounts of knowledge \& information during an educational class, so they prefer learning through activities mostly characterized by interaction and movement, and that their concentration increases when technology is used, they learn and interact in a better manner when using teaching methods characterized by fun and entertainment than traditional methods such as discussion and dialogue. Through these findings resulting from questionnaire analysis, researchers found that students' motivation increases when using teaching methods characterized by fun and entertainment where there classroom interaction, attention and self-confidence increase, so teaching ways must be chosen to be attractive to learners and characterized by motivation and challenge through the innovations of technology. This is available in Gamification which converts lessons or modules to an entertaining game through which students learn with the existence of an atmosphere of fun, enjoyment, challenge and stimulation.

In the light of the above, study problem can be summarized in an attempt to answer the following main question:

How far is Gamification strategy effective in raising motivation among students of second stage of basic education in Muscat, Sultanate of Oman?

The following sub-questions are branched off the above main one:

1. What is the impact of Gamification strategy on raising motivation towards learning for students of the second stage?

2. What is the impact of Gamification strategy on raising the academic achievement of students of the second stage?

\section{STUDY OBJECTIVES}

The current study aims to assess the relationship between Gamification strategy and raising motivation for students of the second stage, where those objectives are specified as follows: 
1. Identifying the relationship between Gamification strategy and raising motivation for the students of the second stage.

2. Identifying the impact of Gamification strategy on raising the achievement level for students of the second stage.

3. The provision of appropriate proposals and recommendations in the light of findings.

\section{STUDY IMPORTANCE}

The importance of the study lies in two aspects as follows:

The theoretical aspect: is providing a conceptual framework about Gamification strategy and its effectiveness on the motivation of students of the second stage.

\section{The practical aspect is as follows:}

1. Providing essential information about the relationship between using Gamification strategy and raising the motivation for learning in order to enhance the academic achievement for students of the second stage, and thus utilizing it in the future as there are no researches in the Arabic language in Gamification and its impact on education.

2. The results of this research benefit competent entities in determining the impact of Gamification strategy on learning and raising the motivation of students towards learning.

3. This research may draw the attention of officials and those in charge of the development of education \& updating learning strategies in determining the criteria for designing such strategy in the most optimal and suitable manner for this category.

\section{STUDY ASSUMPTIONS}

In light of study problem, questions, objectives and importance, the following hypotheses have been set:

1. There are statistically significant differences at the level of significance $(\alpha=0.05)$ between the experimental group and the control group in increasing the motivation for the experimental group.

2. There are statistically significant differences at the level of significance $(\alpha=0.05)$ between the experimental group and the control group in the increase of academic achievement for the experimental group.

\section{STUDY LIMITS}

Spatial limits: "Birkah Bent-Thalabah" Basic Education School (Grades 8-12) in the State of "Al-Seeb" in Muscat Governorate. The reason for the selection of researchers 
for this school is the provision of capabilities required for study, which are a computer lab containing a PC with internet for each student, a display screen and a projector.

Temporal limits: the academic year 2015-2016 AD, the second semester.

Human limits: students of the second stage of basic education, the $9^{\text {th }}$ basic stage.

\section{STUDY METHODOLOGY}

\section{Descriptive analytical methodology:}

For the purpose of assessing the role of Gamification in raising students' motivation to learn, through previous international researches \& studies in the field of Gamification, in which light a game for an educational content has been designed in the subject of science for the ninth stage as well as a questionnaire to measure research variables.

\section{Semi empirical approach:}

Used in research experiment to study the effect of Gamification strategy on raising motivation and academic achievement among the search sample.

\section{STUDY VARIABLES}

The independent variable represented in: the strategy used in teaching, which is Gamification.

The dependent variable represented in:

1. Achievement motivation.

2. Academic achievement.

\section{STUDY TERMINOLOGY}

\section{Gamification:}

According to Hsin \& Others (2013) in her study, the definition of Gamification, as defined by Gamification teacher Yokai Shao, is a "the craft of deriving all elements of fun and thrill elements as well as addictive elements in games and its application to any actual or productive activities".

According to Susan (2013): it is the usage of gaming designs \& mechanisms to improve the non-gaming contexts.

The researchers procedurally define Gamification to be the application of game elements and digital design techniques for games in achieving educational objectives, attracting the attention of learners, raising motivation and solving the problem of low academic achievement. 


\section{Motivation to learn:}

Learning motivation is defined as the desires efforts exerted by the student to achieve a certain level of success and attain the educational objectives (Hamdan, 2006).

Ghobary (2008) defined it as a special case of the general motivation referring to an internal state of the learner pushing him to pay attention to the educational situation, getting to it in a directed activity and continue untill the learning is achieved.

Researchers define motivation as the power that makes the learner want to study and represents the degree obtained by the student in the learning motivation scale by Gamification.

\section{Motivation scale:}

Researchers procedurally defined the motivation scale as the sum of degrees in achievement motivation scale obtained by the responder.

\section{Academic achievement procedurally:}

Researchers defined the academic achievement as the sum of the grades obtained by the student during her answer to pre or post-examinations prepared by the researchers.

\section{The second stage:}

It is an academic educational stage including students aged 11-15 years, and is characterized by hyperactivity and dispersion of attention. This stage is the beginning of forming their independent personalities.

\section{THE THEORETICAL FRAMEWORK \& PREVIOUS STUDIES}

\section{ACADEMIC ACHIEVEMENT}

Academic achievement intensity (2013) is defined as: achieving a certain level of proficiency in the study, whether at school or university, and is determined through standardized examinations or teachers' estimates or both.

Hamada (2010) has defined in his study the concept of academic achievement as: descriptive information showing how much a student has learned out of a subject content, this shall be done through the tests that apply to students during the school year in order to measure knowledge, concepts and skills, i.e. academic achievement is measured by how much students have learned from the course content and how much skills, knowledge and concepts acquired by the student from the subject, and is measured through tests that apply to them during certain periods of time.

Academic achievement is divided according to the classification of (2013) intensity into three sections including: a good achievement in which student performance is higher than his peers through using all capabilities \& capacities that ensure him attain a higher level of achievement performance expected from him. Whilst in case of 
intermediate achievement the grade obtained by the student represents one half of his abilities so that his performance is intermediate and so is the information keeping capacity. For the low educational achievement, the performance of the student is subnormal in comparison with his peers, so that the ratio in which he benefits from his studying is very low.

Many factors affect the academic achievement of the student such as, according to Hamada (2010), the school factors such as the social and physical environment of the school, systems of examinations therein, the student's relationship and compatibility with his colleagues and teachers. The more the teacher is able to know the developmental stages of pupils, their problems and how to deal with it, this affects their academic achievement. There are factors related to the family, the way in which parents deal with children and the impact of this on academic achievement. Other factors are related to the learner himself, his behavior and the extent of his concept about himself, as the way in which he sees himself, as someone who is capable of learning and success, affects his school achievement; other factors are related to the learner himself such as motivation and achievement; the academic achievement is linked to student's motivation so that the stronger the motive a student possesses for achievement, the higher his academic achievement becomes.

Expectations, that are set around the learner and the extent of his academic achievement, negatively or positively differ from what's actually decided because the factor which is responsible for this is a high or low motivation for achievement which is called achievement \& learning motivation (Feki, Mansour, Altwaijri, 2010).

\section{MOTIVATION}

Motivation is considered an important factor in human behavior, a key manifestation of mental health, one of the most complicated issues in the field of psychology \& achievement motivation and a self-goal which activates and directs behavior. Previous studies \& researches suggest that the behavior of individuals is driven and directed by a number of different motives so as to satisfy their biological needs such as hunger, thirst and avoiding pain, in addition to the satisfaction of social needs such as normalization and acceptance.

Achievement motivation is an important component for academic success in all levels of education, from primary school, through high school and finally the undergraduate stage. During the first school years, it is an important motive directing the behavior of the student towards acceptance or avoiding non-acceptance in situations requiring academic excellence. Accordingly, achievement motivation becomes a strong controlling factor in in pupil's school life as the acceptance of teachers to students is mainly based on their continuity to achieve a high level of achievement (Jalali, 2011).

Achievement motivation may be defined as the desire in a good performance to achieve success, so that individuals with a high motivation for achievement tend to 
make serious attempts to get a great deal of success in many different life situations. When studies were carried out on samples of children equal in general mentality and different in achievement motivation level, it was found that the performance of the group with a high achievement motivation was better than the performance of the other group in speed tests of language, math and problem solving; it was also more persistent and more tending to get solutions for situations requiring a solution to the problem and the continuity to work \& diligence even in the absence of external stress. It was also found that they have achieved high levels of success in the secondary and university stages; they tend to occupy prominent positions in the community and ascend above their family origins (Jalali, 2011).

Sherry (2015) in her study referred to the existence of a correlation between each of the academic motivation of all kinds (internal, external and the lack of motivation) with all dimensions and the total grade of academic integration. The researcher explained that the greater the motivation of students to learn and go to school, the more they become integrated \& participating and the more their achievement level increases. The findings of Jassim \& Helw study (2014) showed that there is a relationship between the desire in academic specialization and the academic motivation among university students.

The motivation is a main conditions guiding behavior and acquiring \& learning different skills in different areas of behavior, especially in school learning situations. Therefore, we find it useful to display the most important guiding methods to raise learners' level of motivation, which are as mentioned by Careman (2012):

- An immediate positive reinforcement.

- Directing the attention of students with low motivation to noticing models (examples) with high academic achievement and what they have achieved from his place.

- Effectively enriching academic materials and providing supporting means and activities.

- Developing student's awareness of the importance of learning.

- Highlighting the importance of success in individual happiness in accordance with the positive response.

- Developing innovation and encouraging talents.

- Finding educational solutions student's psychological, health and family problems.

- Positively developing the classroom environment.

- Showing the school in a proper manner in front of the student by the family.

- Taking into account individual differences between learners when dealt by teachers and parents.

Nawal emphasizes in her study (2010) on the existence of a positive relationship between verbal interaction and motivation for learning among students, so teachers and students shall be trained when applying as well as the use of classroom interaction networks to monitor pupils' behavior. 
No doubt that individual's interests, motives and tendencies for the issues that satisfy those concerns are considered as attention directives and thus effectively affect his achievement level. In addition, individual's needs and attitudes are determinants oriented to the selection of interesting things attracting his attention (Jalali, 2012).

\section{GAMIFICATION}

Nearby years has seen a wealth of academic and general publications on effective educational games \& Gamification, which are considered correlated because they are trying to use gaming elements to achieve something beyond playing. Deterding, Khaled, Nacke, \& Dixon (2011) stated that Gamification is an example of serious games so that they defined it as an application of gaming elements for the nonentertaining expected objectives (2015, Richter, Raban, \& Rafaelim).

The study of Dicheva \& Others (2015) reported that Gamification is the use of game design elements in non-play contexts which is a relatively new field and is growing rapidly. Gamification is different from educational game in terms of concept, as the term of Gamification is a very modern term. Its first documented use was in 2008, but has not been widely applied before the second half of 2010, however, there are some elements of Gamification which are not new such as marks and ranks used for a long time in the army since the Soviet era by the Soviet leaders as an alternative for monetary incentives for the performance of work. Commerce is one of the fields that use Gamification widely.

In the light of both studies of Hougan (2015) and Dicerbo (2014), researchers concluded the difference between Gamification and learning by playing, where Gamification differs from learning by playing because it takes the entire learning process and transforms it into a game through the use of gaming elements such as rules \& conditions of play, collecting points, moving to higher levels and the presence of a certain time to play. The following table helps to know the difference between learning by playing and gamification:

\section{Table (1)}

(The difference between learning by playing and gamification)

\begin{tabular}{|l|l|}
\hline Gamification & Learning by playing \\
\hline $\begin{array}{l}\text { Loss ratio is less because the player } \\
\text { collects points on an ongoing basis. }\end{array}$ & There is a high probability of loss. \\
\hline $\begin{array}{l}\text { Gamification is usually cheaper and } \\
\text { easier. }\end{array}$ & $\begin{array}{l}\text { The game can sometimes be expensive } \\
\text { and more difficult at the inception. }\end{array}$ \\
\hline $\begin{array}{l}\text { Does not change much in the content but } \\
\text { just adds a number of features }\end{array}$ & $\begin{array}{l}\text { Content is usually transforming to fit with } \\
\text { the game. }\end{array}$ \\
\hline
\end{tabular}




\begin{tabular}{|l|l|}
\hline $\begin{array}{l}\text { Gamification in education focuses on } \\
\text { points, achievements and rewards. }\end{array}$ & $\begin{array}{l}\text { Points, achievements and rewards are } \\
\text { one component of the educational game } \\
\text { elements. }\end{array}$ \\
\hline $\begin{array}{l}\text { Gamification in itself is a challenge for the } \\
\text { player. }\end{array}$ & $\begin{array}{l}\text { Exerting efforts to provide the right level } \\
\text { of challenge for the player. }\end{array}$ \\
\hline Focus on behavior change. & Focus on changing concepts. \\
\hline
\end{tabular}

The Gamification has an impact on the educational process as it encourages and motivates learners towards education. Darina \& Christo (2015) studied the organizational planning for the application of Gamification in education. Such study supplemented a previous study conducted by Dicheva (2015) aiming to cover all references related to Gamification in the educational process published until June 2014 for the purpose of reviewing the research trends on the application of Gamification in education and how the application is designed to match elements of Gamification. Whilst the new study of Darina \& Christo's supplements that study through a review of research papers published during the year preceding the search (from July 2014 until July 2015) from another direction, to identify changes and guidance emerging from the comparison to results of the previous survey. The study found out that Gamification is a link \& motive which can improve participation, if it has been well planned and organized.

The study of Dicheva \& Others (2015) also emphasized that Gamification has the ability to improve education if it is well designed and used in the right way, so there is a need for more experimental researches, especially in the field of raising learners' motivation to learn by Gamification. It found that the application of Gamification faces some obstacles including: the need for a proper IT infrastructure, the lack of technical support and developing software tools capable of supporting Gamification in the educational field.

Susan (2013) explains that any form of games in a means to increase motivation. This is the most important thing in education, as nothing shows lack of students' motivation like repetition rates in educational institutions every year. There are multiple ways to Gamify education in the classroom, including:

1. Grade Gamification: in which students collect a set of points so that its number is determined at the end of the session, which contributes to motivate students and push them forward.

2. Granting students badges: students are granted a badge for each task they complement. This may seem like a return to the posters of kindergarten and golden stars. This is also applied in Khan Academy, where students are given points \& badges so as to follow their educational progress and increase their motivation. However, it is important to add value to badges such as extra points or progress in a certain skill level. 
3. The integration of educational video games in your course: the use of video games encourage students to continue, to insist on success and to overcome failure, so it will have a high impact on students' motivation when integrated in the educational process.

Creating a competition: games increase competition, raise the morale and enthuses students to participate and interact, where students show an understanding of the material and participation without having to raise their hands as Gamification contributes to increasing the general power in the classroom, motivates students and drives them to interact and compete.

4. Gamification of homework to promote education outside the classroom: this is because of lack of time during the school day, making it difficult sometimes to apply Gamification, so it is possible to convert the homework to the game which will contribute to raise motivation and pleasure for the student when performing the required homework.

With respect to aspects that must be considered to make the Gamification effective in the educational process, Hsin \& Others (2013) illustrates its effective application procedure, namely:

- Understanding the target audience as well as the context to achieve the educational goals of the educational program.

- Identify both public and private educational goals of the educational program.

- The division of the educational program into definite phases so that it makes the goal seem more realized.

- Identifying the resources required to transform phases of the educational program into Gamification.

- Applying Gamification elements: subjective elements (points or achievement levels or drafting of time constraints) and social elements (which are a competition or interactive co-operation such as leaderboards).

\section{Gamification role in raising motivation:}

The motivation for an act is mentioned in social psychology, educational psychology and the organizational science through a set of theories that focus on certain types of environments. Motivation appears in an individual's selection to enter into an activity, the intensity of exerted effort or the insistence on an activity (Rafaeli, Richter, Raban, 2015).

Current comparisons are concerned with two prevailing types playing a role in determining a player's motivation to be internal motivation or external motivation. According to both studies of Deci, Koestner \& Ryan (1999) and Ryan \& Deci (2000), it was illustrated that motivation include two types (internal and external) on one hand by using external awards such as levels and points or badges to improve integration, and also seeks to raise the sense of achievement of efficiency, self-reliance and the sense of belonging (Rafaeli \& others, 2015). 
Ling (2005) proved in his study that the social component is considerably important in games. Competition, social interaction or cooperation may affect the player's behavior. For Vassileva's study (2012), which performed the current comparisons covering a range of external, social and internal motives as per the following figure (1), we note that at one end of the range we put the external motive which is the focus of the theory of Expectation Value and the Strengthening theory for the scientist Skinner. These theories explain the motivation to perform actions or behaviors that lead to external awards (Rafaeli \& others, 2015).

On the other end of the range, Maslow's theory "Hierarchy of needs" focused on the internal motivation and the same for theory of "Achieving the needs" for Atkinson in addition to Pandora's self-sufficiency theory as well as the theory of targets preparing; all these theories are based on need. Theories in mid of the range explain the social motivation of games. In this context, we define Vestinger's theory of social comparison \& self-investment. Each theory is mentioned in the following sections:

Table (2)

(Model of motivation in games based on studies of (Ryan, Deci, 2000), (Vassileva, 2012) and (Rafaeli \& others, 2015))

\begin{tabular}{|c|c|c|}
\hline Internal & Social & External \\
\hline $\begin{array}{l}\text { Based on the need: } \\
\text { - Maslow's hierarchy of } \\
\text { needs } \\
\text { - Need for achievement } \\
\text { theory } \\
\text { - Goal Setting Theory } \\
\text { - Self-sufficiency theory }\end{array}$ & $\begin{array}{l}\text { Based on sociology: } \\
\text { - Social comparison } \\
\text { - Self-investment theory }\end{array}$ & $\begin{array}{l}\text { Based on awards: } \\
\text { - The theory of } \\
\text { expectation value } \\
\text { - Skinner's theory of } \\
\text { strengthening }\end{array}$ \\
\hline
\end{tabular}

Gamification is a concept that can be used to make learning more attractive, but it should not be seen in isolation from other educational aids and teaching methods. There are many educational situations that commensurate with the implementation Gamification both in traditional learning environments and in e-learning environments with careful design commensurate with learners \& educational content properties. One can assess the usefulness of Gamification in education by observing the high level of motivation of learners through Gamification's content of external motivation to students through bonuses pushing them to achieve (Glover, 2013).

In the light of the above, researchers concluded the role of Gamification strategy in raising motivation among students towards education, which positively affects the raise of achievement level; so this research will be applied to determine the impact of Gamification strategy on raising motivation as well as academic achievement among students of the second stage in the governorate of Muscat. 


\section{This study is based on a range of Instructional theories, namely:}

\section{The constructivist theory:}

The constructivist theory emphasizes that a person internally builds his information influenced by the surrounding environment, society and language, however, each learner has a method and privacy in the understanding of information, which may not necessarily be the way adopted by the teacher in the delivery of information to the learner, even if it is confirmed and repeated, it will not be useful in the construction of the information for the learner. This theory is the vision of the theory of learning and child growth, stating that the child is active in building its patterns of thinking as a result of the interaction between innate abilities and the experience (Altelwany, 2014).

One of foundations and principles of learning in the constructivist theory is that inference is a condition to build the concept that is built only on the basis of evidentiary conclusions, and that error is the learning condition where it is an opportunity and situation which when passed builds the right knowledge and the right learning combined with experience not indoctrination.

The constructivism, in its simplest form and most obvious significance, expresses that knowledge is actively built by the learner and not negatively received from the environment. Since Gamification strategy is based on gaming elements in the achievement of all educational objectives of content through these elements, it so makes an active and effective education based on the positive interaction between the student and design effects which is based on Gamification strategy (Altelwany, 2014).

\section{Cognitive theory:}

Cognitive theory implies that the individual experiences are stored in different forms (visual and verbal), it is concerned with mental processes, processors and ongoing interventions on the subject of learning in order to organize and integrate it into the cognitive learning environment. (Kitami, 2013)

One of the principles of cognitive theory in education states that the proper education is the one who which develops the student's skill to solve problems that require the advanced thinking skills such as comprehension, application, analysis, evaluation and creativity. That's where teacher's role starts through providing the means linking new knowledge and such previously acquired knowledge. The learner, according to this theory, is considered active upon reception, understanding and storage of information, remember it in need and use it in a new condition and so learning takes place. (Zouha, 2016)

Where Piaget confirms the importance of achieving balance and consistency between mental operations, conditions surrounding human beings and gamification strategy through adapting educational content, its knowledge and educational objectives to convert it to educational game to be able to react with it; so that he uses his mental abilities to pass different stages and achieve learning. 


\section{RESEARCH METHODOLOGY}

Due to the nature and objectives of the research; the researchers relied on the following two approaches:

1- Descriptive and analytical approach

For the purpose of reaching gamification role in raising students' motivation to learn, through addressing the previous global research and studies in the field of gamification, achieving motivation and academic achievement. In the light of that, a game was designed for the educational content in science course for the ninth grade; in addition to choosing a measure of achievement motivation and pre and post summative assessment.

2- Semi empirical approach

In the application of research to study of gamification strategy impact in raising achievement motivation and raise academic achievement.

\section{RESEARCH EXPERIMENTAL DESIGN}

The used experimental design is based on two groups; experimental group using gamification learning strategy, and a control group using traditional learning strategy. Pre and Post Test shall be applied to the two groups and a measure of motivation. The following table reflects the research experimental design:

Table (3)

(The research experimental design)

\begin{tabular}{|l|l|l|}
\hline Group / processing & Control group & Experimental group \\
\hline Teaching method & Conventional & Gamification \\
\hline Motivation scale & Applied & Applied \\
\hline Pre and post test & Applied & Applied \\
\hline
\end{tabular}

\section{RESEARCH COMMUNITY}

The research community is composed of all students from the ninth grade in primary education Baraka bint Tha'labah primary education girls school (8-12) in Muscat governorate in the second semester of the year 2015/2016 ad.

\section{RESEARCH SAMPLE}

The research sample was selected randomly of 68 female students from the ninth grade and were divided into two groups, a control group of 34 female students and the experimental group of 34 students. 


\section{RESEARCH TOOLS}

1) Rated achievement motivation scale developed by (Dr. Basim Al - Samarrai and Dr. Shawkat Al - Heiazei) in the Khalifa Kaddouri study in 2012.

2) Summative assessment (post and pre) prepared according to certified standards of short tests at ministry of education in Oman; such summative assessment was arbitrated by educational supervisors of science educators in the ministry.

3) Educational game designed according to good evaluation standards of educational software and based on gamification strategy foundations.

\section{RESEARCH PROCEDURES}

To answer research questions, researcher followed these steps:

1- Obtaining official approval by the ministry of education represented at technical office for studies and development in the ministry of education. Then the researchers noticed the general directorate of education for Muscat to apply the study in Baraka bint Tha'labah school ( Grades 812) one schools of Seeb state.

2- Re-rationing achievement motivation scale to fit with age group for the research sample and research community.

3- Preparation of summative assessment, present it to the specialists of the educational supervisors in the science to prove the extent of its reliability and validity.

4- After making sure of the reliability and validity of the scale and summative assessment. It shall be pre and post applied to the research sample which was selected randomly.

5- One lesson of science courses for ninth grade. Then preparing a scenario for converting the educational course to an electronic game.

6- The researchers have communicated with educational specialists in the field of design and production of educational electronic games from the ministry of education to develop an educational game designed according to educational software evaluation standards and on the basis of gamification strategy. ${ }^{1}$

7- Pre and post application results will be considered as achievement motivation scale and summative assessment of research sample.

8- Perform statistical processing on scale pre-results and the test using SPSS program.

\footnotetext{
${ }^{1}$ Mr. Jihad Hadrami (scientific clubs' supervisor in Muscat Governorate) - Activities Department - Educational programs administration - Muscat
} 
9- Prepare computer lab at the school to implement the gamification strategy (gamification) and pre training of using programming.

10-Explain the lesson to the control group using conventional, and explain it to the experimental group using gamification strategy (gamification).

11-The posttest application of achievement motivation scale and summative assessment on the control and experimental groups.

12-Perform statistical processing on scale post-results and the test using SPSS program

13- results analysis, discussion and reporting.

14-Development of proposals and recommendations.

\section{INSTRUCTIONAL DESIGN OF "SCIENCE LESSON" ACCORDING "GAMIFICATION STRATEGY"}

The current research has adopted ASSURE model for instructional design, where prepare this model is one of the most commonly used models on integrating technology in the educational process. This model includes six stages namely; learners' characteristics analysis, setting objectives and standards, teaching strategies, use of teaching aids and technology, demand response from the learner, evaluation and review.

\section{First, Learners' characteristics analysis:}

The research sample characteristics were identified as female students in ninth grade of primary school, aged (14-15). This stage is characterized by learners having the brainpower that help him in excellence, learn the skills, gain the information and the speed of collection; learners also have a tendency toward some courses which are characterized by using problems solving skills, reasoning, conclusion and deciding on matters. In addition; learners have the capacity of analysis and synthesis and also capacity on attention but need to a booster to continue its period. Learners also tend to personal contact and participation of peers in the various activities and have independence and responsibility tendency. They shall have previous experience knowledge about the applied lesson that has been learned in the sixth grade of the primary school, and have the technological skills in dealing with the tools in place (computers, headset, mouse, electronic games); through the questionnaire applied to determine the characteristics of the research community, it was concluded that they have a tendency to self-learning in an atmosphere of fun and interacting with reinforcing elements.

\section{Second, Setting objectives and standards:}

The educational objectives were developed by bloom's classification of cognitive educational objectives ranging from cognitive, applied to the analysis, namely: 
- To mention space invasion moon exploration stages.

- To give the reasons of the existence of some natural phenomena on moon surface.

- To conclude the importance of the giant project of space exploration.

- To master interaction skills with educational software.

- To realize the greatness of the creator concerning the existence of planets and moons in space.

\section{Third, Teaching strategies:}

The use of teaching strategies, gamification strategy (gamification) and individual education of the experimental group that has designed the software based on its standards and foundations, while using discussion and brainstorming and dialogue strategy in the control group.

\section{Fourth, The use of teaching aids and technology:}

Designing software on computer using configure Kodu game lab ${ }^{2}$ program with the experimental group, the software contains pictures, voice and interactive elements. the female students shall interact with the software using mouse and click on pictures of game characters and responding with displayed subject with positive and negative visual and sounds effects according to the learner response; in the presence of continued reinforcement through granting the learner figurative cash rewards.

The teaching aids and tools needed are a computer for each student and educational software based on gamification strategy.

The control group used the traditional teaching methods, such as the board and textbook.

\section{Fifth: Demand response from the Learner:}

According to the gamification strategy (gamification) and individual learning; the educational software will as responses through using events display in sequence and interesting way. When the learner interacts positively with stage, she shall move to the next stage, accompanied by voice and text instructions and directives.

Reinforcement: the software offers figurative bonuses, upon the response and interaction of the learner in a positive or negative way through the stages.

Positive reinforcement: appears directly after the response of the learner, which is a provision of figurative rewards of tokens and move to the next stage.

${ }^{2}$ http://www.kodugamelab.com 
Negative reinforcement: appears directly after the response of the learner, a withdrawal of a part of the tokens reward without moving to the next stage until the learner responds in right way through repetition.

The control group learner responds traditionally through a discussion with the teacher and other students through the dialogue.

\section{Figure (1)}

Screen of the game screens

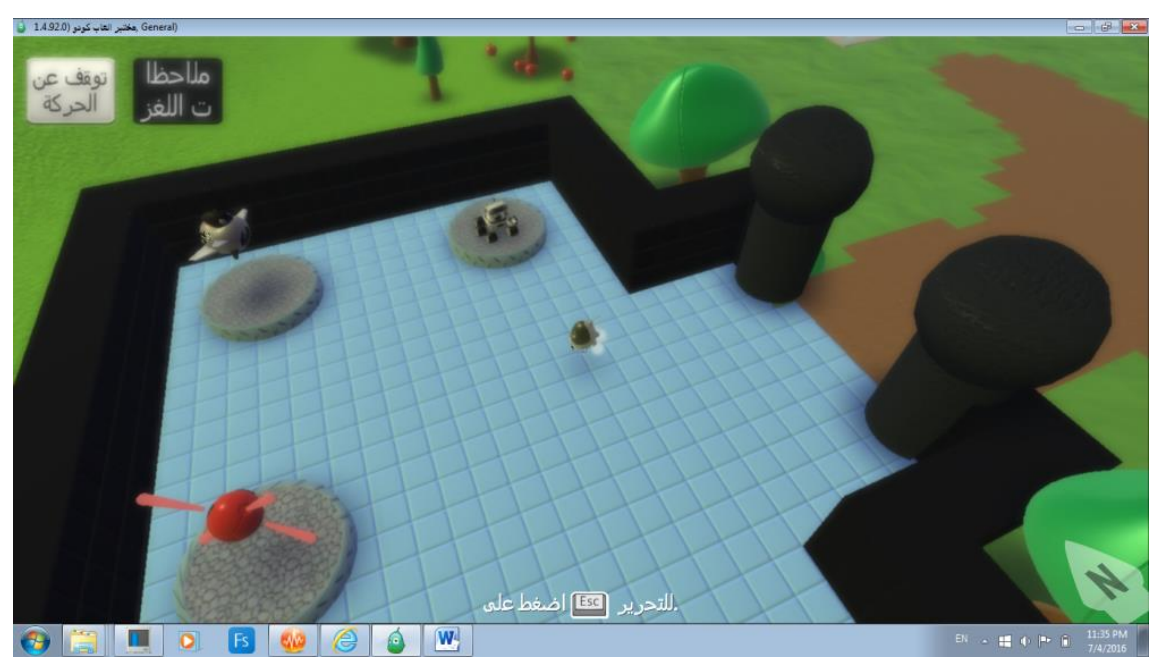

\section{Figure (2)}

Screen of the game screens

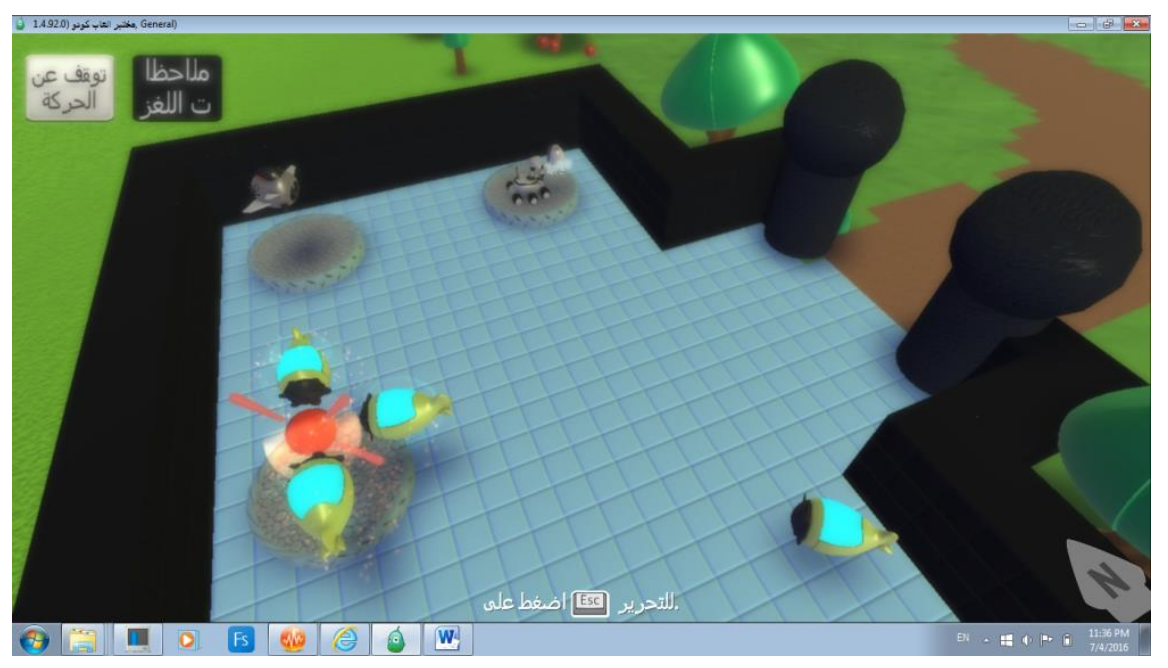




\section{Figure (3)}

Screen of the game screens

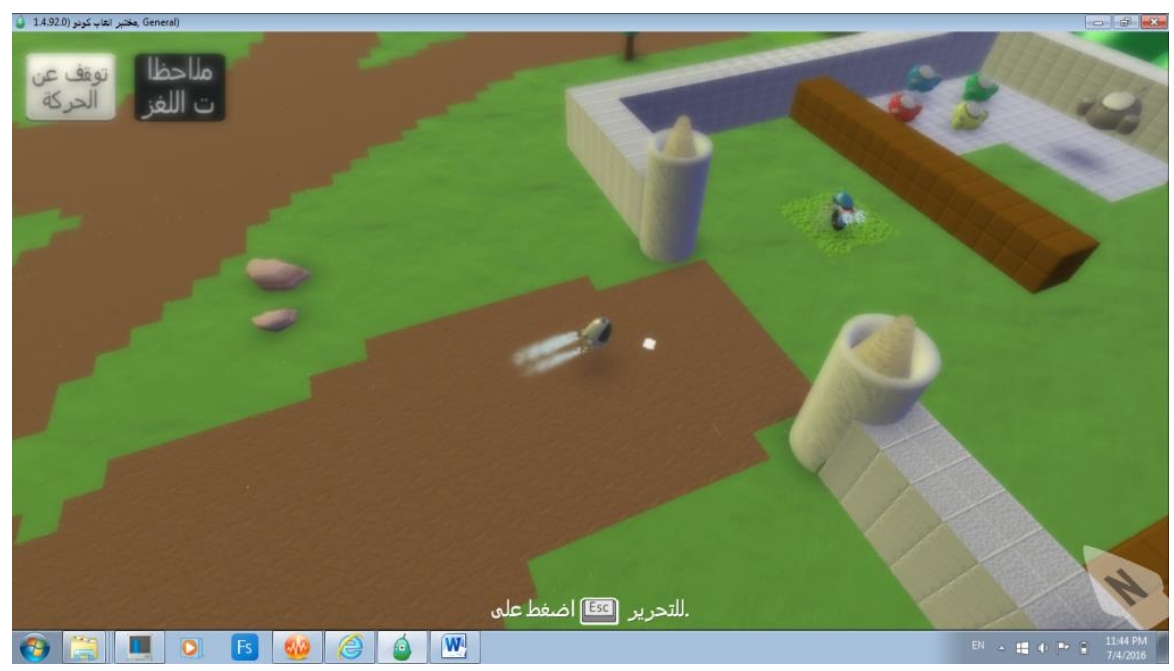

Figure (4)

Students during playing

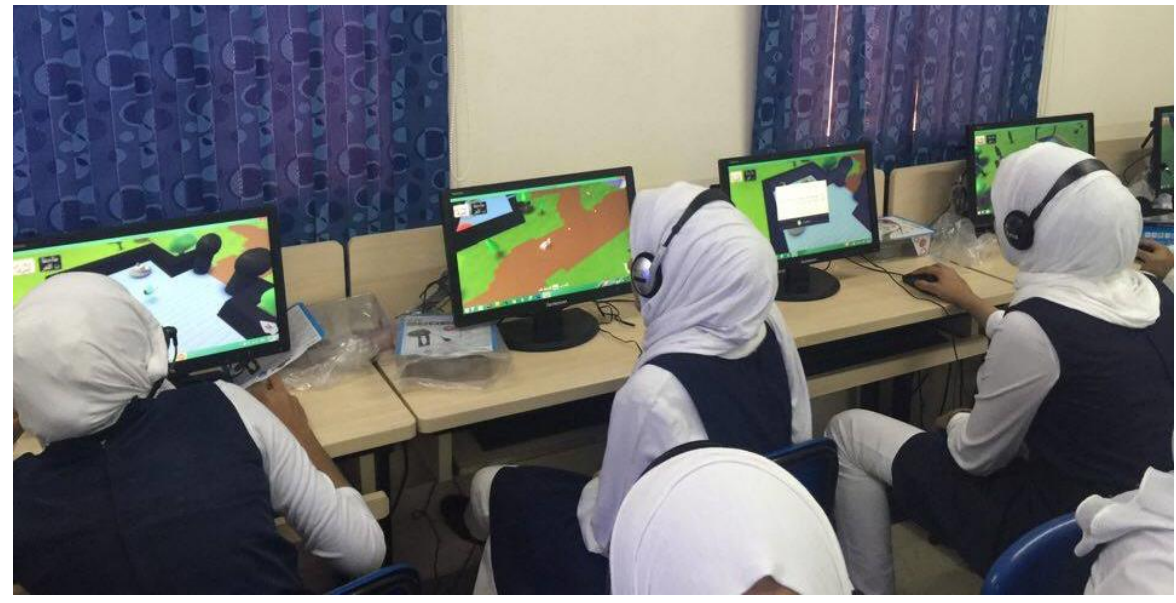

\section{Sixth: Evaluation and review:}

The evaluation has been made through the development of a set of varied questions in each stage of the software, where it is answered by the learner; in addition to the provision of a summative assessment after the completion of the lesson.

The control group shall be evaluated by summative assessment after the end of the lesson.

\section{SEARCH RESULTS REVIEW, DISCUSSION AND INTERPRETATION}

\section{Measurements Reliability:}

Cronbach Alpha reliability coefficient was calculated for each scale to find out the research tools reliability, the reliability coefficient for summative test reached 
0.43 and reliability coefficient of the motivation scale reached 0.93 ; these values are valid for the purposes of the present research.

\section{Verification of Groups Equivalence:}

To verify the equivalence of experimental and control groups. "T" test was used for the independent samples to compare between the two groups in terms of motivation and academic achievement. The results showed no differences in both motivation and academic achievement between the experimental and control groups, which indicates the equality of the two groups. Table (4) shows "T" test results.

\section{Table (4)}

The results of $(\mathrm{T})$ test of the differences between the experimental and control groups in post and pre measure of motivation and academic achievement

\begin{tabular}{|c|c|c|c|c|c|c|}
\hline \multirow[b]{2}{*}{ Variable } & \multicolumn{2}{|c|}{ Experimental group $(\mathrm{n}=30)$} & \multicolumn{2}{|c|}{$\begin{array}{l}\text { Control group }(n= \\
24)\end{array}$} & \multirow[b]{2}{*}{$\begin{array}{l}(\mathrm{T}) \\
\text { Value }\end{array}$} & \multirow[b]{2}{*}{$\begin{array}{l}\text { Potential } \\
\text { value }\end{array}$} \\
\hline & Arithmetic mean & $\begin{array}{l}\text { Standard } \\
\text { deviation }\end{array}$ & $\begin{array}{l}\text { Arithmetic } \\
\text { mean }\end{array}$ & $\begin{array}{l}\text { Standard } \\
\text { deviation }\end{array}$ & & \\
\hline Motivation & 3.08 & 0.91 & 3.06 & 0.92 & -4.49 & .754 \\
\hline $\begin{array}{l}\text { Academic } \\
\text { achieveme }\end{array}$ & 34 & 0.33 & 0.33 & 0.34 & 0.111 & .885 \\
\hline
\end{tabular}

$\mathrm{N}$ = sample size

\section{Research Results Analysis:}

This part includes showing the results of research hypotheses to know the effect of gamification strategy in raising motivation toward learning and academic achievement; the following are the research results.

\section{Results Related to The First Hypothesis:}

There are statistically significant differences at significance level of $(\alpha=$ 0.05 ) between the experimental group and the control group with an increase in the motivation in the favor of the experimental group.

To answer this question, $(T)$ test was used for independent samples to determine if there were statistically significant differences at $(\alpha=0.05)$ between the experimental and control groups regarding motivation level on posttest measurement.

The results showed the existence of statistically significant differences in favor of the experimental group, where effect size indicates that $22 \%$ of variance in motivation is attributable to gamification strategy, and table 5 shows it. 


\section{Table (5)}

(T) Test results of the differences between the experimental and control groups in the post-measurement of motivation

\begin{tabular}{|c|c|c|c|c|c|c|c|}
\hline \multirow[b]{2}{*}{ Variable } & \multicolumn{2}{|c|}{$\begin{array}{l}\text { Experimental } \\
\text { group }(n=33)\end{array}$} & \multicolumn{2}{|c|}{ Control group $(n=24)$} & \multirow[b]{2}{*}{ (T) Value } & \multirow[b]{2}{*}{$\begin{array}{l}\text { Potential } \\
\text { value }\end{array}$} & \multirow[t]{2}{*}{$\begin{array}{l}\text { Effect } \\
\text { Size }\end{array}$} \\
\hline & $\begin{array}{l}\text { Arithmetic } \\
\text { mean }\end{array}$ & $\begin{array}{l}\text { Standard } \\
\text { deviation }\end{array}$ & $\begin{array}{l}\text { Arithmetic } \\
\text { mean }\end{array}$ & $\begin{array}{l}\text { Standard } \\
\text { deviation }\end{array}$ & & & \\
\hline Motivation & 4.29 & 0.37 & 3.44 & 0.67 & 6.06 & 0.000 & 0.22 \\
\hline
\end{tabular}

$\mathrm{N}$ = sample size

\section{Results Related to The Second Hypothesis:}

There are statistically significant differences at the significance level of $(\alpha=$ 0.05 ) between the experimental group and control group an increase in academic achievement in the favor of the experimental group.

To answer this question, $(T)$ test was used for independent samples to determine if there were statistically significant differences at $(\alpha=0.05)$ between the experimental and control groups regarding academic achievement level on posttest measurement. The results showed the existence of statistically significant differences in favor of the experimental group, where effect size indicates that $27 \%$ of variance in academic achievement is attributable to gamification strategy, and table 6 shows it

\section{Table (6)}

(T) Test results of the differences between the experimental and control groups in the post-measurement

of academic achievement

\begin{tabular}{|c|c|c|c|c|c|c|c|}
\hline \multirow[b]{2}{*}{ Variable } & \multicolumn{2}{|c|}{ Experimental $(n=33)$} & \multicolumn{2}{|c|}{ Control group $(n=24)$} & \multirow[b]{2}{*}{$\begin{array}{l}(\mathrm{T}) \\
\text { Value }\end{array}$} & \multirow[b]{2}{*}{$\begin{array}{l}\text { Potential } \\
\text { value }\end{array}$} & \multirow[t]{2}{*}{$\begin{array}{l}\text { Effec } \\
\text { Size }\end{array}$} \\
\hline & $\begin{array}{l}\text { Arithmetic } \\
\text { mean }\end{array}$ & $\begin{array}{l}\text { Standard } \\
\text { deviation }\end{array}$ & $\begin{array}{l}\text { Arithmetic } \\
\text { mean }\end{array}$ & $\begin{array}{l}\text { Standard } \\
\text { deviation }\end{array}$ & & & \\
\hline $\begin{array}{l}\text { Academic } \\
\text { achievement }\end{array}$ & 1.47 & 0.52 & 0.58 & 0.29 & 7.52 & 0.000 & 0.27 \\
\hline
\end{tabular}

$\mathrm{N}$ = sample size 


\section{Discussing Research Results:}

In light of the analysis of previous results; we draw the following conclusions:

1- The presence of statistically significant differences at significance level of $(\alpha=$ 0.05 ) between the experimental group and the control group with an increase in motivation in the favor of the experimental group.

Hence; the researchers conclude raising the achievement motivation of the experimental group on using gamification strategy in comparison with the control group which used conventional method; this is attributable to the provision of fun and challenge atmosphere for the experimental group during learning, in addition to the availability of the proper learning environment for strategy application which led to increased interaction with educational game that helped in motivating the group. This motivation was accompanied by the continued positive reinforcement throughout the learning period and thus increasing achievement motivation for the experimental group.

This proves that the results of the study of both Darina \& Christo (2015) which aimed to study organizational planning of apply gamification at education. This study intended to supplement the precedent study of Dicheva (2015), where their study concluded that gamification is able to motivate students to improve participation if it was planned and organized in good form.

It is also consistent with the result that came in the study (Glover, 2013) which proved that gamification contains an external motivation to the student through the bonuses that motivate him toward achievement and therefore raising the level of motivation of the learner.

In addition; This finding is consistent with the study of Dejatha et al. (2015), which confirmed that gamification contribute to improve education and increase motivation if it is used in the right way.

2- The presence of statistically significant differences at the significance level of ( $\alpha$ $=0.05$ ) between the experimental group and control group with an increase in academic achievement in favor the experimental group.

Hence; researchers conclude raising academic achievement with the experimental group used gamification strategy compared with the control group used the traditional method of teaching due to the increased attention of the students in the experimental group and the high interaction with the educational game; thus increase their integration with educational content. In addition to learning in an atmosphere of fun and challenge which contributes to the stability and consolidation of information in the mind of the learner.

This finding is consistent with Hamada study (2010), which proved that academic achievement is linked to student motivation. whenever the student 
possessed a strong achievement motivation, the higher academic achievement he realizes. Also, this finding is consistent with what came in the Jalali study (2012), which emphasized that students' academic achievement rises in case of paying attention to their needs and motivations and the selection of stimuli that provoke its interest, such matter is used in gamification strategy used in the research, as it used the gaming elements that raised students' attention and increased their motivation.

Research results stressed the results of Sherry study (2015), which proved that there is a correlation between the increase in the motivation of student learning and high academic achievement level. According to this research; the use of gamification strategy contributed in raising the level of motivation among the experimental group and thus raising academic achievement.

\section{RESEARCH RECOMMENDATIONS}

1- Increase the awareness of officials and interested stakeholders and decision makers about the importance of activating the gamification strategy in the Omani curricula.

2- Provide teachers with the necessary workshop trainings for the application of this strategy in the field of education.

3- The application of this strategy in all courses and for all ages and classes.

4- Establish a learning environment through paying attention to infrastructure in schools to increase the effectiveness of the application of this strategy.

5- Conduct researches aimed at studying the impact of gamification strategy in increasing the attention and confidence of the learners.

6- Conduct researches aimed at studying the impact of gamification strategy and the development of higher-order thinking skills and practical skills of learners.

\section{REFERENCES}

Al Feki, Ismail and Mansour, Abdul Majeed and Altwaijri, Mohamed (2010) educational psychology, Riyadh: Obeikan publishing and distribution.

Al Tlwati, Rashid (12/06/2014), the theories of learning: constructivist theory, the article was retrieved on 20 / march / 2016 from the site http://www.new-educ.com/theories-dapprentissage-leconstructivisme

Bedier, Kriman (2012), active learning, Oman, the second edition, Dar Al Masera for publication and distribution. 
Boudiaf, Nawal (2013), classroom interaction and its relationship to motivation for learning among students of the first year - verbal interaction model - educational research journal (ed. 3), 238228.

Chery, Mossad Halim (2015), academic motivation and its relationship with the school integration among Preparatory School students, Arab studies in psychology, 1 (14) 89-162.

Dicerbo , Kristen ( 2014 / April 14 ) , 5 Differences Between Education Games and The Gamification Of Education, Article Retrieved March 20 / 2016 From http://researchnetwork.pearson.com/digitaldata-analytics-and-adaptive-learning/5-differences-education-games-gamification-education

Dicheva ,D \& Dichev ,C ( 19 / October 2015 ) Gamification in Education : where Are We in 2015 ? paper Presented at World Conference On E- learning , Kona, Hawaii .

Dicheva, D., Dichev C., Agre G., \& Angelova G. (2015). Gamification in Education: A Systematic Mapping Study. Educational Technology \& Society, 18 (3), 75-88.

Ghabbary, Thaer (2009). The psychology of human growth between childhood and adolescence. First Edition, Arabic society library, Jordan.

Glover, lan (2013) Play As You learn : Gamification as a Technique for Motivating Learners, Sheffieled Hallam University, United Kingdom .

Hadda, Lounas (2013), academic achievement relation with learning motivation for the teenager. field study for students in the fourth year, unpublished master thesis, Ackley Mohand Oolgaj university, Bouira, Algerian republic.

Hamada, Walid (2010). Sons ill treatment and neglect and its relationship with academic achievement (field study on students of the first secondary year class at official schools of Damascus governorate). Damascus university Magazine, Volume 26.

Hamdan, Mohammed (2001). Learning and Achievement assessment. Education Dar, ed.5.

Hougan, Sean ( 2015 ) , Gamification Vs .Game Based Learning in e learning , Article Retrieved Maech 20 , 2016 from http://blog.lambdasolutions.net/gamification-game-based-learningelearning

Hsin , w., Huang , Y., \& Soman , D ( 2013 ) Apractitioners Guide To Gamification of Education , Rotman School of Management, University Of Toronto .

Jalali, Lamaan (2011), academic achievement, Oman, the first edition, Dar Al Masera for publication and distribution.

Jassim, Khaled and Helw, Ali (2014), specialization desire and its relationship to academic self motivation among university students, Arts magazine, ed. (109) 609-640

Kitami, Joseph (2013), cognitive theory in education, Amman: Dar Al Masera for publication and distribution.

Motivation scale was used for the rated achievment which was developed by (Dr. Basim Al - samarrai and Dr. Shaukat alheiizqui in the study _ Khalifa, Kaddouri (2012), satisfaction with academic guidance and its relationship with achievement motivation of the students of the second 
secondary year. A field study in Hassi Khalifa Secondary school, Al wadi State, unpublished Master Thesis, university of Mouloud Mammeri, Tizi Ouzou, Algeria.

Richter ,G., Raban ,D.\& Rafaeli , Sheizaf ( 2015 ) , studying Gamification : The Effect of Rewards and Incentives On Motivation, Springer International Publishing Switzerland, University of Haifa.

Suzanne ( 2013 , July 15 ) 4 Ways TO Bring Gamification of Education To Your Classroom , Article Retrieved In March 20 - 2016 from http://blog.tophat.com/4-ways-to-gamify-learning-in-yourclassroom/

Zouha, Najib (06/03/2016), learning theories: a comparison between the behavioral and cognitive and constructivism, the article is retrieved on 20 / march / 2016, from http://www.neweduc.com/\%d9\%85\%d9\%82\%d8\%a7\%d8\%b1\%d9\%86\%d8\%a9-\%d8\%a8\%d9\%8a\%d9\%86$\% \mathrm{~d} 9 \% 86 \% \mathrm{~d} 8 \% \mathrm{~b} 8 \% \mathrm{~d} 8 \% \mathrm{~b} 1 \% \mathrm{~d} 9 \% 8 \mathrm{a} \% \mathrm{~d} 8 \% \mathrm{a} 7 \% \mathrm{~d} 8 \% \mathrm{aa}-$ \%d8\%a7\%d9\%84\%d8\%aa\%d8\%b9\%d9\%84\%d9\%85 